\title{
THE FUTURE OF EUROPE*
}

\author{
Prof. Dr. Emile NOËL**
}

It is a great pleasure and honour for me to take this opportunity to speak again in the framework of the European Community Institute of Marmara University.

I would like to speak on the new developments in the European Community implementation of the Maastricht Treaty and its consequences in the short and medium terms with respect to future enlargements of the Community, including Turkish application.

\section{Political Cooperation}

The Maastricht Treaty has been in force for less than five months only and until now, the changes it introduced are not very significant, except perhaps in the wording. Its implementation will be a slow process and in some cases, its real impact will appear only through the practice. I shall try today to select some of the main points, in order to evaluate their possible consequences on the present Community and later, on the prospects for its enlargement including the specific problem of Turkey.

First, some words on the so-called "political part" of the Maastricht Treaty, the "second pillar" of the European Union, in the Brussels jargon, related to the "common external and security policy". Even if this topic was a major one for Chancellor Kohl and President Mitterand when they made the proposal to negotiate on a Political Union in 1990, it was not possible during the '91 negotiations to overcome the existing deep opposition within the Twelve, both on the existence of a European identity within NATO and on the way of managing external and security matters within the European Union.

The mix of European Union, Western European Union and NATO, eventually agreed with the "benign consent" of the United States, is probably more procedural than really operative.

- Paper presented at the Recent Developments in European Union and Turkey - EU Relations Conference of the Marmara University European Community Institute.

** President of the European University Institute, former Secretary General of the EC Cornmission 
In the field of foreign and security policy, Britain with the support of some other countries, refused definitely communitarization, or even any attempt to communitarize as suggested by the founding members of the Community. The final compromise was adopted at the lowest level: the level of wording. The Treaty states formally that a "common external and security policy" is established and defines its general aims. However, its implementation will only be the result of "common actions" to be decided unanimously in every part, with the only exception that the Twelve can, when implementing such a common action, decide unanimously that some questions are to be approved by majority.

What can be a common policy, in a field so sensitive and moving as foreign policy, when decided and managed unanimously by 12 (and soon 16) countries except that it is a non-policy. With bright words, in fact, the Maastricht Treaty only confirmed and strengthened lightly, on some procedural points, what has been attained since 1970 by the so-called "political cooperation" and has gained legal force in 1987, through the Single European Act. The basic principles and the content (intergovernmental cooperation, unanimous agreement, no institutional control) were not changed. Perhaps, in the coming years, under the pressure of international events, the Twelve -or the sixteen- will be obliged to cooperate more strongly and efficiently than in the past, but it will not be the real consequence of the new wording of the Maastricht Treaty.

\section{Institutional Changes}

Some of the institutional changes in the Community system have, on the contrary, a real substance. In some cases, the first steps of this implementation were even taken during the last weeks. I intend to select some of these issues, which can have middle-term or long-term consequences.

First of all, the role and powers of the European Parliament will be significantly increased in two major fields, through the new co-decision procedure and with respect to the appointment of the European Commission.

The co-decision procedure, which will be used for a significant number of questions requires the common agreement of the Ministerial Council and of the Parliament to adopt Community rules or directives.

A Conciliation Committee with equal members of Ministers and MEPs will have to draft compromise proposals, to be submitted for approval (without any change) both to the Council and the Parliament.

This new power of the Parliament is strenghtened by an enlargement of the existing assent procedure, in force since 1987, for membership Treaties and associa- 
tion agreements which will be extented to the conclusion of any international agreement of significant importance to the Community.

The implementation of this new procedure is now beginning During the last session of the Parliament, more than twenty co-decision files were discussed. A first meeting of a Conciliation Committee was held at the beginning of this month. If the co-decision procedure has some effective results in the coming months, it will be an important political test before the election of the European Parliament which will be held in June.

A second important step for the European Parliament is its new power in the appointment procedure of the European Commission. The approval of the European Parliament will be requested on the Commission as a whole, before it will be appointed by the member governments. In a previous stage of the procedure, the EP had to give an advice on the nomination of the president of the Commission. The final approval to be obtained gives its full weight to this advice in the beginning of the procedure. This new procedure will be implemented during the second half of this year for the renewal of the European Commission, the mandate of which is ending on January 5, 1995. The mandate of the new Commission will be the same as the mandate of the European Parliament: five years.

This change will impose in a major way, a political control of the Parliament on the Commission. At the same time, the political stature of the European Commission will be significantly enhanced since the appointment of the Commission will be subject to scrutiny and approval of the European Parliament.

All these changes (legislative powers of the Parliament and appointment procedure of the Community) will significantly modify in the future the relations between the Commission and the European Parliament as well as the Commission and the Council and the Parliament. The Parliament will be a new and increasingly important factor. Some crises are to be expected before the new system will be finalized, but at the end of the decade, it will be significantly different from the old CommissionCouncil dialogue of the last forty years.

\section{Economic and Monetary Union}

The structural changes are much more important in the chapters of the Maastricht Treaty related to the Economic and Monetary Union.

The European Central bank to be created before the end of the century, in 1999 in principle -will have very large powers to manage the single European currency- in fact much larger powers than the European Commission or the European 
Parliament in their field of European competence and it will be the most "European" body of the Community.

With twelve members in the European Monetary Union, there will be only six persons in the Directorate of the Bank (this number will be reduced if only some of the members of the Community can take part in the European Monetary Union.)

The golden rule in force for the European Commission since the beginning, that a citizen of each country has to be member of the Commission wil not be applied for the Directorate of the Bank. Moreover, the members of the ruling body of the Monetary Union, the Council of Governors of the Bank are the Governors of the national Central Banks plus the members of the Directorate under the chairmanship of the president of the Bank. This council will decide in the field of monetary policy by majority voting, both the Governors of the National Central Bank and the members of the Directorate, having one vote each. How far are we from the present Council of Ministers with weighted votes, a seventy percent majority and the members of the Commission present but without a right to vote.

\section{Differentiation}

A last key point is the differentiated structure of the Maastricht Treaty. Even if there were some cases of differentiation in the past (the main one being the special rule for the British contribution to the budget), everybody tried to minimize or to hide them as shameful derogations.

In the Maastricht Treaty, the differentiation was the basis of the final agreement, of the final compromise on some of the most important issues. For example the social rules can now be decided or enforced through eleven members only (without Britain). The Monetary Union will be implemented in 1999 only by the members being in line with the common criteria stated in the Treaty. Both Denmark and Britain, through special protocols, will not be able to enforce certain important parts of the Treaty, i.e. the Monetary Union, and the Social Charter, unless they join in.

A new political principle is now in force. If it is not possible to compel any Member State to take part in every progress or development of the Community but no Member State can prevent its partners to go ahead if they intend to do so. The only condition is that every country can join its partners later when possible for it economically and/or politically. So possibly in the future a hard core Community can be developed -if some Members are prepared to create a closer political and economic union between themselves. 


\section{Enlargement}

So this improved Community will now have to meet the challenge of enlargement, the present one (Austria, Finland, Norway and Sweden) and the next one, I think in a rather near future.

As far as the present enlargement is concerned, the Twelve decided in Lisbon in June 1992 to exclude any institutional change, except arithmetical adaptations. The changes in depth are to be discussed during a new intergovernmental conference in 1996 (as stated in the Maastricht Treaty) with the new Member States. Such a time-table is the worst possible one. How can those countries which will have obtained, sometimes very painfully, through referendums, the approval of their membership, on the basis of the present institutional system, agree to a change in depths of this system some months later?

Whatever can be the outcome of the 1996 negotiations, the Community needs a fresh view of its institutional developments. Independently of the applications already submitted (Turkey, Cyprus, Malta), the Community will be obliged to give clear answers to requests for greater Europe from Central and Eastern European countries. A new enlargement will make a fundamental change of its institutional system unavoidable.

The Community, in the past, committed itself in the Ankara Treaty to give positively oriented answers to the applicant and others (Cyprus and Malta) and to the Central and Eastern European countries (The Copenhagen meeting of the European Council). I am personally convinced that the Community will not escape the political need to give in the coming years -before the end of the decade-clear prospects to its European friends and neighbours claiming membership. The political pressures will be increasing in the near future with the expected move of Hungary, Poland and the Czech Republic.

\section{The Prospects of Developments}

What kind of a system can be appropriate for twenty or more countries deeply different economically as well as in respect of their legal, political or cultural customs?

I think we need to study some of the institutional changes inscribed in the Maastricht Treaty, in order to find if they are convenient to build larger Europe, more flexible, more democratic, more manageable. The improved role of the European Parliament, a lighter institutional structure, the differentiation of committments beyond the common basis (with the possibility of a hard core of countries preferred to 
go ahead) can be some of the key points of any research.

In particular, in a differentiative system, the range of powers and duties managed in common would be adjusted on the basis of economic abilities and (in some cases) of the political commitments. Such a system can only work if there does exist, first a common basis of rules, rights and obligations, and second solidarity measures to support the economic and social progress of the less developed countries. The internal market and its supporting common policies can be such a common basis but for some of the new members a rather long transitional period will be needed as was in the first enlargement and in the 1957 Rome Treaty. However, the new members will take part in the new institutional system and from the beginning will benefit from the solidarity measures of the Community, the Structural Funds of the Community.

The political part of the common basis could include a large amount of political cooperation and cooperation in justice and internal affairs. In the same time, some of the Twelve or perhaps Sixteen member countries, could progress further towards monetary union and perhaps political union in common and foreign security policy.

The functioning of the "common basis" will need to be improved to become more democratic and more flexible. There will be a long way to convince the member states to adopt such a change as the present difficulties of the level of the blocking majority in the enlarged Community have proved. But the ideas implemented in the Maastricht Treaty, as I explained before, could be a basis for a discussion of such an improvement in the future.

\section{Prospects for Turkey}

Taking into account such possible developments, what to do in respect of Turkish application for membership of the Community? The request was submitted in 1987 by Minister Ali Bozer on behalf of the Turkish Government, at a time which perhaps was not the most appropriate and the answer was politely delayed. I think that a new and strong political pressure to obtain a clear answer -could be the opening of the negoiations- must be done when the second enlargement, the enlargement to a "Greater Europe" will be a new on the forefront of the Community affairs and only at that time. In practice when the Community will be prepared to discuss the Central European applications (Hungary, Poland, Czech Republic, for example), Turkey must make every effort to join this group. There can be good economic and political reasons for a joint treatment.

If no clear answer is given at that time, the scheme of Customs Union, should, in my opinion, be discussed again. An association on the basis of a Customs Union, when fully implemented includes a lot of administrative, economic and political con- 
straints, when the associated member does not take part in the decision - making process, except on a consultative basis. Such a position can be acceptable for a short time before full membership. It cannot be sustainable if membership is delayed again. In such a case, a Free Trade Area system could be much more convenient as it was in the case of Austria, Finland, Norway and Sweden, since mid $1970 \mathrm{~s}$.

I am conscious of the 1995 obligation agreed by the Turkish Government for the implementation of the Customs Union and, I suppose, Professor Ali Bozer can explain this part in more details. Surely, important steps must be taken at this moment, but the full implementation of the Customs Union and of its consequences in the field of commercial policy, preferential agreements, supporting policies including competition rules, state subsidies, public procurement which will need much more time and a reappraisal if needed and I hope it will not be the case, can be managed later. 